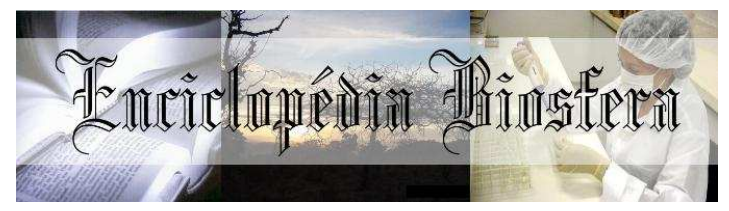

\title{
ARTRITE INFECCIOSA EM FRANGOS DE CORTE
}

Daniella Rodrigues da Costa ${ }^{1}$, Eliete Souza Santana ${ }^{2}$, Karyne Oliveira Coelho $^{3}$

${ }^{1}$ Médica Veterinária, Discente do Mestrado em Desenvolvimento Rural Sustentável, Universidade Estadual de Goiás, Câmpus São Luís de Montes Belos, GO, Brasil, Bolsista FAPEG - Fundação de Amparo e Pesquisa de Estado de Goiás;

${ }^{2,3}$ Médica Veterinária, Docente do Mestrado em Desenvolvimento Rural Sustentável, Universidade Estadual de Goiás, Câmpus São Luís de Montes Belos, GO, Brasil, darocostavet@gmail.com

Recebido em: 03/10/2016 - Aprovado em: 21/11/2016 - Publicado em: 05/12/2016 DOI: 10.18677/EnciBio 2016B 007

RESUMO

A avicultura industrial tem o desafio de aumentar a produção de aves e manter a sanidade do plantel. A artrite infecciosa em frangos de corte é uma enfermidade que causa inúmeros prejuízos econômicos, pois além de desvalorizar o lote, as aves deixam de se alimentar, constitui uma das causas de condenação em abatedouros, pois as carcaças doentes são condenadas total ou parcialmente. Entretanto, as perdas econômicas são contabilizadas apenas dentro dos abatedouros e não há contabilização das perdas ocorridas nas granjas. Para controlar essa enfermidade, medidas de biossegurança devem ser estabelecidas, com base nos seus agentes etiológicos, formas de transmissão e de controle. Os principais agentes etiológicos envolvidos na patogenia das artrites infecciosas são Mycoplasma, Ortheoreovirus aviário, Pasteurella spp., Salmonella sp., Escherichia coli e Staphylococcus spp.. O conhecimento desses patógenos se faz necessário para diminuir as perdas econômicas, pois conhecer o agente possibilitará a implantação de medidas preventivas e corretivas nas granjas, estabelecendo programas de controle para diminuir o risco de disseminação em níveis aceitáveis, bem como oferecer alimento de qualidade aos consumidores. Com base no exposto, foi realizada uma revisão de literatura com o intuito de trazer informações relacionadas aos principais agentes etiológicos envolvidos na gênese da artrite infecciosa em frangos.

PALAVRAS-CHAVE: articulação, avicultura, carcaça, condenação

\section{INFECTIOUS ARTHRITIS IN BROILERS}

\begin{abstract}
The poultry industry has increasing challenge the poultry production and keep the sanity of the squad. An infectious arthritis in broiler and a disease that cause numerous losses economic, because in addition to devalue the lot, because as birds leave to food, is one of the condemnation causes abattoirs in because as carcasses patients are condemned partially total or. However as economic losses are accounted only to the abattoirs and there is no accounting of losses occurred in the farms. To control this disease, biosecurity measures should be established, based in your etiologic agents, transmission and control methods. The main etiological agents involved
\end{abstract}


in the pathogenesis of infectious arthritis are Mycoplasma, Ortheoreovirus aviary, Pasteurella spp., Salmonella spp., Escherichia coli and Staphylococcus spp.. The knowledge of these pathogens is necessary paragraph lower as economic losses, because knowing the agent allow for a preventive and corrective measures Implementation of the farms, establishing control programs paragraph decrease spread risk at acceptable levels, as well as offer for consumers one quality food. Based in the exposed, was carried out a literature review in order to bring information to related main etiological agents in the source of infectious arthritis in broilers.

KEYWORDS: articulation, carcass, conviction, poultry

\section{INTRODUÇÃO}

A fome é uma preocupação mundial e oferecer alimentos seguros a todos é uma das premissas da Organização das Nações Unidas para Agricultura e Alimentação (FAO), que tem como objetivo principal aumentar a produção de alimentos. O mundo consome cada vez mais proteína de origem animal, o que leva ao aumento da demanda de carne de aves, pois sua produção é a de menor custo e em menor tempo quando comparada as outras espécies animais, o que a torna de suma importância para o combate à fome.

Diante dos aspectos abordados, faz-se necessário investir em alguns itens dentre os quais a sanidade, qualidade na produção, rações balanceadas, manejo adequado dos aviários, melhoramento genético, incentivos fiscais, aumento na produção de grãos, instalação de grandes agroindústrias de alimentos baseadas no sistema de integração e preço, que são fatores que contribuem para o aperfeiçoamento e consolidação do setor avícola (TAVARES \& RIBEIRO, 2007; BRASIL, 2016 a). De acordo com KUCHENNY \& MORAES (2009) e BACK (2010), o crescimento da indústria avícola traz consigo desafios, como manter a sanidade do plantel e mesmo com a evolução tecnológica da avicultura de corte, certas enfermidades ainda são causas de perdas produtivas elevadas.

CORDEIRO et al. (2012) citaram que os problemas locomotores impedem as aves de se locomoverem, o que prejudica o bem estar, a produtividade e determina lesões e os prejuízos econômicos ultrapassam milhões de reais e são incompatíveis com a competitividade da avicultura. A redução das perdas é fundamental sendo necessário conhecer os gargalos produtivos durante o processo e aumentar a quantidade de informações sobre boas práticas de manejo que ainda são escassas. Deve-se então direcionar os esforços para reduzir as perdas e aumentar a lucratividade do produto final. Os problemas locomotores, perda de peso, pior conversão alimentar, tratamentos com antibioticoterapia e aumento da mortalidade são algumas das causas de prejuízos econômicos que ocorrem em aves.

Um exemplo de patologia que causa as perdas acima citadas é a artrite infecciosa que na avicultura industrial é um problema sanitário e econômico que provoca grandes perdas nos processo de produção e industrialização, sendo uma das causas de condenação patológica mais frequente em abatedouros frigoríficos (RECK et al., 2012). Na mesma temática, SILVA \& VIEIRA (2010) descreveram que os prejuízos econômicos ultrapassam milhões de reais e são incompatíveis com a competitividade da avicultura. A redução das perdas é fundamental. É necessário conhecer os gargalos produtivos durante o processo produtivo e a quantidade de informações sobre boas práticas de manejo ainda é escassa. Deve-se então direcionar os esforços para reduzir as perdas e aumentar a lucratividade do produto final. 
MASCHIO \& RASZL (2012) avaliaram o impacto financeiro das condenações post mortem em abatedouro de aves na região sul do país, sob regime de Serviço de Inspeção Federal (SIF) no período de um ano, onde a condenação por atrite representou $1,74 \%$ (2.636.278 de aves) do percentual de causas de condenação. Os autores concluíram que a empresa estudada deixou de ganhar $\mathrm{R} \$ 1.708 .095,16$, com condenação de aves, sendo $R \$ 678.089,45$ perdidos devido às condenações totais $(2,78 \%)$ e $\mathrm{R} \$ 1.030 .005,71$ por condenações parciais $(97,22 \%)$ das condenações.

FERREIRA et al. (2012), descreveram que entre 2009 e 2011 ocorreu um crescimento de $43,81 \%(R \$ 256.691,78)$ nas perdas devido a condenação total de carcaça de frangos em abatedouros sob SIF no Rio Grande do Sul. LIMA et al. (2014) avaliaram o impacto econômico das perdas devido a condenações de carcaças em um abatedouro frigorífico sob Serviço de Inspeção Estadual (SIE) na cidade de Conceição da Feira - Bahia, e concluíram que no período de um ano perdeu-se $\mathrm{R} \$ 494.015,18$ por condenações de carcaças de frango. As condenações post-mortem totais representaram $17 \%$ e as parciais $83 \%$ do total condenado durante $\mathrm{o}$ ano, sendo as perdas econômicas diárias foram em média foram de $\mathrm{R} \$ 2.277,00$.

EBLING \& BASURCO (2016) descreveram que as condenações totais por artrite foram de $0,69 \%$ em Santa Catarina, 0,37\% no Paraná, 0,28\% em São Paulo e $0,55 \%$ no Rio Grande do Sul, em estudo realizado no ano de 2011 . Das aves destinadas a condenação, $12,29 \%$ teve condenação total que causaram um prejuízo econômico de aproximadamente $\mathrm{R} \$ 33.986 .528,79$, enquanto $87,71 \%$ tiveram condenação parcial.

Considerando o exposto, foi realizado um estudo acerca da artrite infecciosa em frangos de corte, pois torna-se necessário o conhecimento dos agentes etiológicos envolvidos na patogenia dessa enfermidade, com o objetivo de diminuir os prejuízos causados pela mesma. Esses prejuízos têm ocorrência na propriedade rural, devido ao uso de tratamento e morte de animais doentes; no abatedouro, pelo descarte parcial ou total das carcaças e na comercialização através das barreiras sanitárias impostas por países consumidores da carne de frango.

\section{DESENVOLVIMENTO}

\section{A Avicultura Brasileira}

O setor avícola brasileiro é um segmento moderno e estimulado por políticas públicas e inovações tecnológicas que visam aumentar a produtividade e o faturamento das indústrias avícolas. Em 1970 iniciaram-se as exportações e no século XXI, o Brasil tornou-se um dos maiores exportadores mundiais de carne de frango. Hoje o Brasil é segundo maior produtor mundial de carne de frango e em 2015 a produção chegou a 13,14 milhões de toneladas (ABPA, 2016 c).

CORDEIRO et al. (2012); MENDES (2014) e ABPA (2016 b) descreveram que o Brasil é líder em exportação, com mais de três milhões de toneladas do produto exportado, que chegam a 155 países e representam $40 \%$ do mercado mundial da carne de frango. Paraná, Santa Catarina e Rio Grande do Sul são os principais estados fornecedores e o Centro Oeste, devido a grande produção de soja e milho, grãos constituintes da ração e que representam $70 \%$ do custo de produção, está em crescimento no setor avícola e ocupa o sexto lugar em produção da carne de aves. 
A produção cresce e representa $47 \%$ das carnes produzidas no Brasil, sendo que o crescimento do mercado está balizado pelas melhorias de produtividade, na alta tecnologia, na genética, no manejo e na ambiência aplicados nas granjas avícolas (ABPA, 2016 b; BRASIL, 2016 a).

MENDES (2014) relatou que o mercado avícola corresponde a $1,5 \%$ do PIB brasileiro, gera cinco milhões de empregos diretos e indiretos e as exportações chegam a 8,5 bilhões de dólares. O Brasil possui algumas vantagens na produção da carne de frango frente a outros países, dentre estas o custo de produção baixo, programas de biossegurança eficientes que garantem a sanidade dos plantéis e a produção baseada no sistema de integração.

Outro fator importante, para o crescimento do setor avícola é o país possuir o Programa Nacional de Sanidade Avícola (PNSA), implantado desde 1994, ano de sua publicação através da Portaria № 193, de 19 de setembro de 1994, que tem como objetivos prevenir, controlar ou erradicar as principais doenças de interesse em avicultura e saúde pública, definir medidas para a certificação sanitária e fornecer produtos avícolas seguros para o mercado interno e externo (BRASIL, 2014).

Em 2015 no Brasil, a média de consumo de carne de frango por pessoa era de $43,25 \mathrm{~kg}$ por habitante, pois o mercado interno absorve a maior parte da produção avícola, sendo que o crescimento e fortalecimento deste setor são alavancados pelas exportações de carne de aves (ABPA, 2016 a). Já nos Emirados Árabes, maiores consumidores mundiais, a média de consumo se aproxima dos 70 $\mathrm{Kg} / \mathrm{habitante}$ (LISITA, 2016).

Quanto à exportação, $57,7 \%$ da carne de aves exportada são em cortes, $32,6 \%$ de aves inteiras, $4,2 \%$ de produtos salgados $3,7 \%$ em alimentos processados e $1,8 \%$ na forma de embutidos. Os pés das aves são considerados um subproduto com pouco valor no Brasil, porém são comercializados como especiarias nos mercados asiáticos, que são os maiores compradores e consumidores de pés de frango no mundo (MENDES, 2014).

Em 2013, a China tornou-se o mercado externo consumidor mais importante para as exportações brasileiras, seguida de outros países do Leste da Ásia (Japão e Hong Kong), do leste do Pacífico do Oriente Médio (Arábia Saudita, Emirados Árabes), dos Estados Unidos e da América Latina, que juntos consomem metade da carne de frango brasileira exportada (OECD \& FAO, 2015; LISITA, 2016).

Com o crescimento do mercado consumidor da China, que é comprador dos pés de aves, faz-se necessário um estudo aprofundado sobre as causas de artrite infecciosas, pois estas causam condenação dos pés e grandes perdas econômicas diretas devido à morte dos animais, diminuição de produção pela dificuldade de locomoção, despesas com medicamentos e perdas econômicas indiretas nos abatedouros como desvalorização do lote e implantação de barreiras comerciais (NÄÄS et al., 2010).

De acordo com COELHO (2006); REVOLLEDO \& FERREIRA (2009), as alterações no sistema musculoesquelético, que é afetado pelo rápido crescimento das aves, pela nutrição e pelo manejo subdividem-se em doenças metabólicas, alterações post-mortem, de desenvolvimento, adquiridas, do metabolismo pigmentar, circulatórias e inflamatórias. Já as alterações articulares podem ser post-mortem, de desenvolvimento, degenerativas, pigmentares, circulatórias, inflamatórias e neoplásicas e o rápido crescimento das aves, em conjunto com defeitos de manejo e de nutrição comprometem os ossos e os músculos. 
Segundo NÄÄS et al. (2010), as inúmeras pesquisas na produção de aves é o que explica a alta produtividade da espécie, comparada as outras espécies animais. Porém, apesar dos frangos crescerem fisiologicamente, o tecido ósseo dos mesmos, não acompanham na mesma velocidade de crescimento, o que leva a diversos problemas locomotores, desconforto e perda do bem-estar. As aves se comportam de maneira diferente do esperado, quanto ao consumo de água e alimento, com isso, o animal deixa de ganhar peso, diminui a eficiência produtiva e a sanidade. A sintomatologia clínica mais comum de problemas locomotores é a claudicação, que pode estar acompanhada de raquitismo, discondroplastia tibial, degeneração femoral, desvios de coluna e problemas articulares.

Estudos para avaliar a qualidade microbiológica dos pés de frango são necessários, pois de acordo com BRIZIO et al. (2013) este produto, tem importância comercial para o mercado asiático, que é um grande comprador, porém, o Brasil não possui legislação específica para avaliar a qualidade microbiológica dos mesmos. Neste contexto a artrite é a inflamação de uma ou várias articulações, comum nos animais domésticos e podem ser classificadas quanto ao curso em aguda e crônica, quanto a causa em infecciosa e não infecciosa e quanto ao exsudato que pode ser seroso, fibrinoso, hemorrágico ou purulento (COELHO, 2006).

Macroscopicamente, observa-se aumento de volume na articulação afetada, sendo a articulação tibiometatarsiana a mais afetada, o líquido sinovial pode estar de seroso a caseoso, de acordo com a cronicidade do processo. Quanto às membranas sinoviais, na artrite aguda se apresentam avermelhadas enquanto que na artrite crônica, apresentam-se endurecidas (COELHO, 2006).

O mesmo autor descreveu que microscopicamente, é possível observar fibrina e hemácias no exsudato e, em casos mais críticos, pode haver a presença de heterofilos com a formação de exsudato caseoso, pois estas células não são capazes de produzir pus.

As sintomatologias clínicas da doença são apatia, perda de mobilidade dos membros, perda de peso, dor e ancilose em casos crônicos. As aves doentes devem ser eliminadas do plantel, pois tornam-se portadoras (COELHO, 2006; BACK. 2010). COELHO (2006) descreveu que quanto à causa, as artrites podem ser infecciosas ou não. As infecciosas podem ser causadas por vírus (reovírus), por micoplasmas e por bactérias (Pasteurella spp., Salmonella sp., E. coli, Staphylococcus spp.). Já MOREIRA et al., (2009), descreveram o reovírus, Mycoplasma synoviae e Staphylococcus spp. como os principais agentes infecciosos das artrites. Porém RECK et al. (2012), descrevem apenas o reovírus e os Mycoplasmas como os causadores da doença.

Segundo MOREIRA et al. (2009); MASCHIO \& RASZL (2012); MOURA et al., (2012); OLIVEIRA et al. (2016), a artrite está entre as principais causas de condenação de aves em abatedouros.

\section{Artrite causada por vírus}

Atrite viral, também denominada Reovirose é uma doença infecciosa, causada pelo reovírus, com importância para frangos de corte e reprodutoras pesadas que tem como característica principal a presença de lesões nas articulações do tarso e do metatarso. É uma doença que geralmente apresenta-se de forma subclínica, que dificulta o diagnóstico e o tratamento, e facilita a disseminação da doença (BACK, 2010).

A Reovirose ou artrite viral é causada pelo vírus Orthovirus (antigamente era denominado Reovírus), do gênero Orthoreovirus, da família Reoviridae, com 10 
sorotipos que expressam patogenicidade diferentes. Cada sorotipo infecta uma espécie animal diferente. O vírus é envelopado, o que lhe traz a característica de resistir no ambiente, e dificulta sua destruição. É caraterizada por lesões inflamatórias crônicas em articulações, porém também foi relacionado com problemas entéricos que levam à síndrome da má absorção e a complicações em doenças respiratórias (REVOLLEDO \& FERREIRA, 2009; BACK, 2010).

BACK (2010) descreveu que o primeiro isolamento do vírus ocorreu em 1954 nos EUA no trato respiratório e em 1957 foi isolado de articulações de aves com artrite, que também eram portadoras assintomáticas de Mycoplasma synoviae. Nos dias atuais a presença do vírus é endêmica nos plantéis de aves comerciais.

O mesmo autor descreveu que, após a contaminação da ave ocorre uma viremia e o vírus pode ser isolado de diversos órgãos tais como fígado, rim, baço, pulmões e articulações. VASCONCELOS et al. (2001); COELHO (2006); BACK (2010) descreveram que as rotas de contaminação causam sintomas e períodos de incubação variados.

VASCONCELOS et al. (2001) relataram que na primeira semana após inoculação do vírus, independente da via de inoculação, observa-se inflamatório mononuclear e heterofílico na bainha tendinosa do tendão flexor digital. Na segunda semana, o infiltrado torna-se na sua totalidade mononuclear, com necrose do tecido tendíneo, aumento das áreas afetadas, com desorganização das fibras colágenas dos tendões. Junto ocorreu proliferação das células das membranas sinoviais com formação de folículos linfoides no tecido do tendão. Já na terceira semana após a inoculação, observou-se intensificação da resposta do tecido linfóide e formação de projeções vilosas na membrana sinovial, devido à hiperplasia das células sinoviais.

Ainda de acordo com os mesmos autores, a lesão da membrana sinovial progride pela inserção tendínea em direção a cartilagem articular, que permaneceu íntegra. A hiperplasia das células sinoviais com formação de vilosidades, fibroplasia e fibrose do tecido tendíneo, com nódulos fibróticos e folículos linfóides nas vilosidades aumentam, conforme a progressão da doença.

Segundo VASCONCELOS et al. (2001), aves inoculadas pelo coxim plantar têm multiplicação viral no local, antes de ocorrer a disseminação do vírus pela corrente circulatória. Nas aves inoculadas via oral, o vírus multiplica-se primeiro no epitélio intestinal e atinge a circulação sanguínea pelas placas de Peyer no trato digestivo. $O$ tropismo do reovírus e sua replicação nos fibroblastos pode explicar a cronicidade das lesões, fase que ocorre substituição do tecido tendíneo por tecido fibroso.

Os animais mais susceptíveis têm entre quatro e sete semanas de vida e são do sexo masculino. A doença é aguda o e vírus tem predileção pelo tendão gastrocnêmico e as membranas periarticulares (COELHO, 2006; BACK, 2010), porém a mortalidade é baixa, sendo que nas manifestações clínicas a mortalidade pode chegar a $5 \%$ e pode ser aumentada em aves com infecções conjuntas com Mycoplasma spp., Staphylococcus spp. e E. coli que podem agravar os quadros de artrite.

Nos achados macroscópicos, tem-se exsudato de cor amarelada que pode evoluir para exsudato caseoso quando ocorre infecção secundária. As proximidades das articulações apresentam hemorragias petequiais. A sintomatologia clínica observada é claudicação, dificuldade de locomoção, decúbito ventral e apatia com aumento de volume do membro atingido. As aves acometidas morrem por inanição e desidratação. A transmissão ocorre por contato entre as aves, aerossol, equipamentos, fômites e trânsito de pessoas, pois o vírus é excretado pelo sistema 
respiratório e digestivo e o mesmo permanece nas tonsilas cecais e articulações por vários dias (VASCONCELOS et al., 2001; COELHO, 2006; BACK, 2010; MOR et al., 2013; MOR et al., 2014).

O diagnóstico é feito com os sinais clínicos da doença, juntamente com o isolamento do vírus. Não existe tratamento eficaz, e o mesmo é realizado com antibioticoterapia para diminuir os microrganismos secundários presentes no mesmo quadro. A prevenção é feita através de vacinação contra o Orthoreovírus via água de bebida, alimento ou nas matrizes, sendo que neste caso o objetivo é a proteção do ovo (VASCONCELOS et al., 2001; COELHO, 2006; REVOLLEDO \& FERREIRA, 2009; BACK, 2010; BARRIOS et al., 2012; MOR et al., 2013; MOR et al., 2014).

\section{Artrite causada por Mycoplasmas}

De acordo com BACK (2010) micoplasmose é o nome da infeção causada pela bactéria do gênero Mycoplasma, da família Mycoplasmataceae. É considerada a menor bactéria que pode ser cultivada em meios artificiais. Cora-se com Giemsa, sendo fracamente Gram negativa. $O$ fato de não possuir parede celular, dificulta a sobrevivência no meio ambiente e a torna sensível à maioria dos desinfetantes, porém é resistente a antibióticos que agem na parede celular. São mais de 20 espécies infectantes de aves, porém, apenas duas são de interesse para a avicultura industrial, no que se refere a caso de artrites infecciosas, sendo estes o Mycoplasma gallisepticum (MG) e Mycoplasma synoviae (MS).

BAO et al. (2014) descreveram o MS como um patógeno de aves que causa infecções do trato respiratório e atrite em galinhas e perus, sendo que esta patologia causa inúmeras perdas econômicas na indústria avícola devido ao retardo de crescimento, queda na produção de ovos, diminuição da eclodibilidade dos ovos, condenação de carcaças no abate, maior custo financeiro com o controle da doença e predispõe a diminuição da imunidade nas aves, facilitando a disseminação de outras doenças nos animais acometidos.

Segundo REVOLLEDO \& FERREIRA (2009) e BACK (2010) a micoplasmose é uma doença com distribuição mundial nos plantéis de aves. Os hospedeiros naturais do microrganismo são galinhas, perus e galinhas d'angola. O período de incubação da doença varia de 11 a 21 dias, de acordo com a virulência do microrganismo, os fatores ambientais e o estresse. A transmissão ocorre de forma horizontal, através do contato direto com secreções respiratórias ou verticalmente através do oviduto e a aves permanecem portadoras por vários meses, tornando-se fontes de contaminação.

De acordo com BACK (2010), o tratamento com antibiótico não tem sucesso, porém, o tratamento de ovos férteis através da imersão ou injeção de antibióticos leva ao nascimento de pintos livres de micoplasmas. O aquecimento dos ovos a temperaturas elevadas causa morte de alguns embriões, porém, destrói a grande maioria dos micoplasmas, e é usado como um método alternativo para controle da doença. A forma de controle citada por REVOLLEDO \& FERREIRA (2009) foi à vacinação, porém, quando o quadro clínico se agrava, os sacos aéreos são afetados, e esse agravamento geralmente ocorre com a doença ou vacinação contra Newcastle, bronquite infecciosa ou ambas as vacinações. Por serem de difícil tratamento e controle a erradicação de todo plantel é a forma mais eficiente de controle.

Segundo BACK (2010) e CASAGRANDE et al. (2014) o Mycoplasma gallisepticum (MG) é a espécie mais patogênica e de maior importância causadora de micoplasmose aviária. É caracterizada como uma doença do trato respiratório. 
Clinicamente os animais apresentam-se prostrados, com dificuldade respiratória, tosse, espirros, secreção nasal, sinusite e aerossaculite, sendo denominada Doença Respiratória Crônica.

De acordo com MACHADO et al. (2012) com o crescimento anual da avicultura e o aumento das exportações, cuidados com a sanidade do plantel avícola são cada vez mais necessários, pois agentes com o MG afetam negativamente 0 ganho de peso e a qualidade das carcaças no abate, o que leva a inúmeros prejuízos para o setor avícola.

REVOLLEDO \& FERREIRA (2009), BACK (2010) e RECK et al. (2012) descreveram, que as aves acometidas por Mycoplasma synoviae apresentam doença infecciosa caracterizada por infiltração das membranas sinoviais, tendinite exsudativa, bursite esternal e artrite. Os surtos ocorrem quando a granja não adota as medidas de biossegurança preconizadas pelo PNSA. Nas aves jovens ou quando associadas a outros patógenos a doença se torna mais grave. A transmissão do MS ocorre principalmente pela via vertical e a transmissão lateral, de ave para ave também tem grande importância, sendo a contaminação por contato direto, inalação, equipamentos, fômites, introdução de aves positivas no plantel e através do homem. Animais jovens são mais susceptíveis. Os sinais cínicos são sinovite, edema das articulações, principalmente na tibiotársica com o tarso metatarso, claudicação, palidez de crista, acúmulo de exsudato viscoso nas membranas sinoviais e nos tendões, perda de peso e calo de peito devido ao decúbito. A mortalidade é baixa e pode aumentar quanto existem agentes patogênicos secundários atuando concomitantemente. A infecção subclínica do aparelho respiratório superior é a sintomatologia mais comum da doença.

Histologicamente, visualizaram-se infecções em diferentes órgãos e tecidos, tais como baço, fígado, coração e moela que se encontram hiperplasiados. $O$ infiltrado inflamatório linfohistiocitário difuso com acúmulo de heterófilos ocorre nas cápsulas articulares, membrana sinovial e tendão flexor digital. O diagnóstico baseiase nos sinais clínicos, principalmente nas articulações. A detecção do DNA por métodos moleculares e PCR (Reação em cadeia polimerase) são os meios de diagnóstico mais utilizados e diferencia os tipos de micoplasmas. Tratamento em granjas deve ser feito com antibioticoterapia. Para prevenção e controle é necessário adquirir animais livres de MS (REVOLLEDO \& FERREIRA, 2009; BACK, 2010).

\section{Artrite causada por bactérias}

\section{Pasteurella spp.}

A Pasteurella spp. é uma bactéria Gram negativa, aeróbica, bacilo, imóvel, anaeróbico facultativo que causa a cólera aviária. Não é resistente no ambiente, porém as aves que se recuperam se tornam portadoras e disseminadoras da bactéria. É uma doença aguda com alta morbidade e alta mortalidade. Possui antígenos somáticos e capsulares. $\mathrm{Na}$ infecção crônica, o agente coloniza as articulações e os seios infraorbitários. A bactéria possui uma cápsula que auxilia na invasão do sistema imune, devido a ação antifagocitária. As endotoxinas virulentas contribuem para a invasão e multiplicação do patógeno (BACK, 2010).

BACK (2010) descreveu que a doença ocorre em aves por todo mundo e nas infecções agudas, a ave pode morrer sem manifestar sinais clínicos. As aves acometidas raramente têm menos de seis semanas de idade e apresentam-se prostradas, penas arrepiadas, corrimento nasal, fraqueza e anorexia. Pode haver 
aumento de barbela com necrose. Nas infecções crônicas, aparecem lesões inflamatórias nas patas e articulações das pernas. O diagnóstico definitivo é feito através do isolamento e identificação do agente. $O$ controle é feito com antibioticoterapia e a prevenção é realizada através de boas práticas de manejo e adoção de medidas de biossegurança.

\section{Salmonella sp.}

Salmonelose é a infecção causada por bactérias do gênero Salmonella, da família Enterobacteriaceae. São bacilos Gram negativos e possuem mais de 2500 sorotipos que infectam o homem e os animais, sendo que as infecções por Salmonella sp. em três grupos. No grupo um estão a $S$. Gallinarum e a $S$. pullorum, causadoras do tifo aviário e da pulurose respectivamente, que são imóveis e hospedeiros específicos de galinhas e perus, sendo as de maior patogenicidade. No grupo dois estão as $S$. entérica subespécie entérica, que são móveis e causam a paratifo aviária e são encontradas em animais clinicamente sadios. No grupo três estão as $S$. entérica subespécie entérica dos sorovares Enteritidis e Typhimurum, que são móveis e podem causar doença nos animais (BACK, 2010; FILHO et al., 2016).

REVOLLEDO \& FERREIRA (2009) citaram que as aves jovens apresentam sinais clínicos mais do que aves adultas. As aves apresentam-se apáticas, com penas arrepiadas, asas caídas, com anorexia, diarreia e empastamento da cloaca. $\mathrm{OH}$ et al. (2010) descreveram que a Salmonella Enteritidis causa alta mortalidade e morbidade de plantéis de frango de corte por todo mundo e que os animais acometidos apresentam artrite purulenta.

MOREIRA et al. (2008), afirmam que a Salmonella sp. está presente nos plantéis goianos, em consequência, estando presente nos alimentos destinados à comercialização no mercado interno e externo, sendo necessárias ações governamentais mais rígidas no controle e monitoramento do microrganismo em questão, pois a contaminação, constitui-se em um risco para a saúde pública.

\section{Escherichia coli}

A E. coli é uma bactéria Gram negativa, do tipo bacilo, que não forma esporos e causa a colibacilose. É de fácil isolamento e pouco exigente quanto ao meio de cultura. Seu crescimento ocorre em temperaturas entre 18 a $44^{\circ} \mathrm{C}$, sendo a temperatura ótima de $37^{\circ} \mathrm{C}$. Os sorotipos são baseados nos diferentes antígenos da cápsula $(\mathrm{K})$ e somáticos $(\mathrm{O})$ da parede celular. Os sorotipos mais relacionados com doenças de aves são $\mathrm{O} 1: \mathrm{K} 1, \mathrm{O} 2: \mathrm{K} 1,078: \mathrm{K} 80$ e $\mathrm{O} 35$ sendo a colibacilose é responsável por um grande número de condenações de carcaças de aves causando milhões de dólares de prejuízo as industrias anualmente (BACK, 2010).

BACK (2010) descreveu que a colonização das células intestinais e a produção de toxina variam de acordo com a cepa envolvida e a idade do animal acometido. A E. coli é encontrada no intestino dos animais e é eliminada nas fezes.

Os animais que sobrevivem após terem colibacilose têm retardo de desenvolvimento e serão portadores e veículo para transmissão da bactéria para outros lotes. Clinicamente observa-se dificuldade de locomoção, decúbito, enterite, artrite, onfalite, aerossaculite e sinovite (BACK, 2010; KNÖBL et al., 2008; BACK, 2010). O tratamento é feito com antibioticoterapia, a prevenção e controle são baseados nas medidas de manejo sanitário. Com a cronicidade da doença ocorre formação de material caseoso que pode estar presente por todo o interior da carcaça (BACK, 2010). 
MOURA et al. (2012), descrevem a colibacilose como a terceira maior causa de condenação total em abatedouro em Minas Gerais sob regime do SIF, sendo que - microrganismo pode ser agente secundário de infecções respiratórias, que apresentam-se na forma clínica como artrite, sinovite, osteomielite e peritonite.

\section{Staphylococcus spp.}

Conforme descrito por BARROS et al. (2011), a estafilococose é uma das doenças mais comuns em aves, e a maioria das infecções são causadas por Staphylococcus coagulase positiva, principalmente pelo Staphylococcus aureus que é uma bactéria Gram positiva, em forma de cocos e é saprófita. A formação de biofilme é um dos principais mecanismos de infecção da bactéria e tem relação com a aderência da bactéria. $O$ biofilme inibe a quimiotaxia, a fagocitose e a proliferação dos linfócitos, como consequência os macrófagos atuam de forma limitada, o que dificulta o combate do agente pelo organismo animal. Nas aves o $S$. aureus, causa várias doenças, inclusive artrite. No geral, a doença ocorre quando há diminuição da resistência do animal e apresenta-se como uma infecção secundária.

Os principais sintomas são náuseas, cólica, vômito, prostração e desidratação (RODRIGUES et al., 2008). RASHEED (2011) descreveu que aves de corte infectadas com Staphylococcus aureus apresentam sinais clínicos de depressão, inchaço nas articulações, dificuldade de locomoção, sendo que esta dificuldade ocorre em várias aves com artrite. Ao corte das articulações é possível observar que o líquido sinovial apresenta-se amarelo escuro, tendendo para turvo. O tratamento é feito com antibioticoterapia, porém sem resultados satisfatórios, pois é comum a resistência. A prevenção é feita através de medidas de manejo e biossegurança (BACK, 2010).

\section{CONSIDERAÇÕES FINAIS}

A produção de carne de frango está em constante aumento no Brasil com objetivo de atender a demanda do mercado interno e o crescimento do mercado externo.

Com a intensificação da produção é necessário implementar programas de controle de patógenos, para garantir a sanidade dos plantéis, diminuir a níveis aceitáveis o risco de disseminação de doenças, bem como oferecer alimento de qualidade aos consumidores.

Os prejuízos econômicos causados pelas condenações parciais ou totais das aves diagnosticadas com artrite nos abatedouros são incompatíveis com a tecnificação do setor e a identificação dos principais agentes etiológicos envolvidos nas artrites infecciosas de frangos. O conhecimento desses patógenos poderá possibilitar a aplicação de medidas preventivas e de controle nas granjas, além do planejamento estratégico para diminuição das perdas econômicas causadas por esta patologia, bem como, a diminuição dos custos com tratamento das aves doentes e das perdas financeiras pelas condenações parciais ou totais das carcaças.

\section{REFERÊNCIAS}

ABPA. Associação Brasileira de Proteína Animal. Relatório Anual 2016. Disponível em <http://abpa-br.com.br/storage/files/versao_final_para_envio_digital_1925a_final_ abpa_relatorio_anual_2016_portugues_web1.pdf>. Acesso em: 03 set. 2016 a. 
ABPA. Associação Brasileira de Proteína Animal. Resumo do Setor. Disponível em < http://abpa-br.com.br/setores/avicultura/resumo >. Acesso em: 01 abr. 2016 b.

ABPA. Associação Brasileira de Proteína Animal. Resumo do Setor. Disponível em < http://abpa-br.com.br/noticia/informes/todas/producao-de-carne-de-frango-totaliza13146-milhoes-de-toneladas-em-2015-1545>. Acesso em: 01 abr. 2016 c.

BACK, A. Manual de Doenças das Aves. Cascavel: Back, 2010.

BAO, S.; GUO, X.; YU, S.; DING, J.; TAN, L.; ZHANG, F.; SUN, Y.; QIU, X. ; CHEN, G.; DIN, G. Mycoplasma synoviae enolase is a plasminogen / fibronectin binding protein. BMC Veterinary Research, London, v. 10, n. 223, p. 1-9, 2014. Disponível em <http://www.biomedcentral.com/1746-6148/10/223>. doi:10.1186/s12917-014-0223-6

BARROS, M. R.; COSTA, M. M.; FRANÇA, C. A.; SAUKAS, R. N.; SILVA, L.B. G.; SILVA, V. A.; CAVALCANTE, R. V.; MOTA, R. A. Perfil de resistência a antimicrobianos de Staphylococcus spp. isolados de frangos de corte e poedeiras comerciais no Estado de Pernambuco. Pesquisa Veterinária Brasileira. Seropédica - RJ, v. 3, n. 8, p. 672-676, agosto 2011. Disponível em < http://www.scielo.br/scielo.php?pid=S0100736X2011000800007\&script=sci_abstract \&tlng=pt >. DOI:10.1590/S0100-736X2011000800007.

BARRIOS, P. R.; MARIN, S. Y.; RIOS, R. L.; PEREIRA, C. G.; RESENDE, M.; RESENDE, J. S.; MARTINS, N. R. S. A retrospective PCR investigation of avian Orthoreovirus, chicken infectious anemia and fowl Aviadenovirus genomes contamination in commercial poultry vaccines in Brazil. Arquivo Brasileiro de Medicina Veterinária e Zootecnia. Belo Horizonte - BH, v. 64, n. 1, p. 231-235, 2012. Disponível em < http://www.scielo.br/scielo.php?script=sci_arttext\&pid=S010209352012000100035\&l ang=pt > DOI: 10.1590/S0102-09352012000100035.

BRASIL. Ministério da Agricultura pecuária e Abastecimento. Programa de Sanidade Avícola completa 20 anos. Disponível em: <http://www.agricultura.gov.br/ comunicao/noticias/2014/10/programa-de-sanidade-avicola-completa-20-anos $>$.Aces so em: 09 dez. 2014.

BRASIL. Ministério da Agricultura pecuária e Abastecimento. Aves. Disponível em<http://www.agricultura.gov.br/animal/especies/aves>. Acesso em: 09 abr. 2016 a.

BRIZIO A. P. D. R., SALLES, B. P., PRENTICE C. Avaliação microbiológica de pés de frango destinados ao consumo humano Microbiological evaluation of chicken feet intended for human consumption. Semina: Ciências Agrárias, Londrina - PR, v. 34, n. 6, p. 2847-2852, nov./dez. 2013. Disponível em < http://repositorio.furg.br/handle/1 /4497>.

CASAGRANDE, R. A., CASTRO, L. A., ROLIM, V. M., WOUTERS, F., BOABAID, F. M., SOUZA, S. O., GUERRA, P. R., SILVA, S. C., DRIEMEIER, D. Diagnóstico imuno-histoquímico e caracterização anatomopatológica de Mycoplasma gallisepticum em galinhas de subsistência. Pesquisa Veterinária Brasileira. Seropédica - RJ. v. 34, n. 2, p. 153-161, 2014. Disponível em < http://www.scielo.br/scielo.php?script=sci _arttext\&pid=S0100-736X2014000200010> DOI: 10.1590/S0100-736X20140002000 
10.

COELHO, H. E. Patologia das Aves. São Paulo: Tecmed, 2006.

CORDEIRO, A. F. S., BARACHO, M. S. , NÄÄS, I. A., NASCIMENTO, G. R. Using data mining to identify factors that influence the degree of leg injuries in broilers. Revista Engenharia Agrícola, Jaboticabal - SP, v.32, n.4, p.642-649, jul./ago. 2012. Disponível em < http://www.scielo.br/scielo.php?script=sci_arttext\&pid=S010069162012000400003> DOI: 10.1590/S0100-69162012000400003.

EBLING, P. D. BASURCO, V. Análise das perdas econômicas oriundas da condenação de carcaças nos principais estados brasileiros produtores de frangos de corte. Ciências Agroveterinárias e Alimentos. Itapiranga - SC, v.1, p.1-11, 2016. Disponível em < http://revista.faifaculdades.edu.br:8080/index.php/cava/article/view/ 193/88>.

FERREIRA, T. Z.; SESTERHENN, R.; KINDLEIN, L. Perdas econômicas das principais causas de condenações de carcaças de frangos de corte em MatadourosFrigoríficos sob Inspeção Federal no Rio Grande do Sul, Brasil. Acta Scientiae Veterinariae. v. 40, n.1, p. 1021, 2012. Disponível em < http://www.ufrgs.br/actavet/401/PUB\%201021.pdf>.

FILHO, R. A. C. P., FERREIRA, J. C., KANASHIROIV, A. M. I. DARINI, A. L. C. BERCHIERI JUNIOR, A Antimicrobial susceptibility of Salmonella Gallinarum and Salmonella Pullorum isolated from ill poultry in Brazil. Ciência Rural, Santa Maria RS, v.46, n.3, p.513-518, mar, 2016. Disponível em < http://www.scielo.br/scielo.php ?script=sci_arttext\&pid=S010384782016000300513\&lang=pt> DOI: 10.1590/0103-8 478 cr20150398.

KNÖBL, T., GODOY, S. N., MATUSHIMA, E. R., GUIMARÃES, M. B., FERREIRA, A. J. Caracterização molecular dos fatores de virulência de estirpes de Escherichia coli isoladas de papagaios com colibacilose aviária. Brazilian Journal of Veterinary Research and Animal Science. São Paulo - SP, v. 45, n. 1, p. 54-60, 2008. Disponível em < http://www.revistas.usp.br/bjvras/article/view/26729. DOI: 10.11606/S1413 $-95962008000700007$.

KUCHENNY, F.B. e MORAES, F.R. Coccidiose em frangos de corte: Revisão de literatura. PUBVET, Londrina, v. 3, n. 15, Art\#564, 2009. Disponível em: $<$ http://www.pubvet.com.br/texto.php?id=564>.

LIMA, K. C.; MASCARENHAS, M. T. V. L.; CERQUEIRA, R. B. Técnicas operacionais, bem estar animal e perdas econômicas no abate de aves. Archives of Veterinary Science. Londrina - PR, v.19, n.1, p.38-45, 2014. Disponível em < http://revistas.ufpr.br/veterinary/article/view/32027> DOI: 10.5380/avs.v19i1.32027.

LISITA, P, Avicultura em Goiás: um bom negócio doméstico. Disponível em:<http://www.avisite.com.br/clipping/index.php?codclipping=21331>. Acesso em: 09 abr. 2016. 
MACHADO, L. S.; NASCIMENTO, E. R.; PEREIRA, V. L. A.; ALMEIDA, D. O.; SILVA, R. C.F.; SANTOS, L. M. M. Mycoplasma gallisepticum como fator de risco no Peso de lotes de frangos de corte com condenação por aerossaculite na Inspeção Sanitária Federal. Pesquisa Veterinária Brasileira. Seropédica - RJ. v. 32, n. 7, p. 645-648, 2012. Disponível em < http://www.scielo.br/scielo.php?script=sci_arttext\&p id=S0100-736X2012000700010 > DOI: 10.1590/S0100-736X2012000700010 .

MASCHIO, M. M.; RASZL, S. M. Impacto financeiro das condenações post-mortem parciais e totais em uma empresa de abate de frango. Tecnologias para Competitividade Industrial. SENAI. Florianópolis - SC, p. 26-38, 2012. Disponível em < http://revista.ctai.senai.br/index.php/edicao01/article/view/208> DOI: 10.18624/etech.v0i0.208.

MENDES, A. A. Associação Brasileira de Proteína Animal. Panorama da avicultura nacional e perspectivas do setor. Brasília - DF, 21 out. 2014.

MOURA, M. S.; REIS, D. O.; CARREON, R. S.; DE ARAÚJO; L. B. ARAÚJO; M. F. C. CARRIJO; K. F.; CARDOSO, R. Causas de condenações post-mortem de perus abatidos em estabelecimento com Serviço de Inspeção Federal (SIF) no estado de Minas Gerais, Brasil. Revista Brasileira de Ciência Veterinária. Niterói - RJ, v. 19, n. 1, p. 7-12, jan./abr. 2012.n Disponível em < http://www.uff.br/rbcv/ojs/index.php/ rbcv/article/view/17/pdf> DOI: 10.4322/rbcv.2014.075.

MOR, S. K., SHARAFELDIN, T. A., PORTER, R. E., ZIEGLER, A., PATNAYAK, D. P., GOYAL, S. M. Isolation and Characterization of a Turkey Arthritis Reovirus. Avian Diseases. Washington DC, v. 57, n. 1, p. 97-103. March 2013. Disponível em < http: //www.ncbi.nlm.nih.gov/pubmed/23678736> DOI: 10.1637/10353-090712-Reg.1.

MOR, S. K., VERMA, H. , BEKELE, A. Z. , SHARAFELDIN, T. A. , PORTER, R. E. , GOYAL, S. M. One-Step Real-Time Reverse Transcription-PCR for the Detection of Turkey Reoviruses. Avian Diseases. Washington DC, v. 58, n. 3, p. 404-407. September 2014. Disponível em <http://www.pubpdf.com/pub/25518435/One-step-realtime-reverse-transcription-PCR-for-the-detection-of-turkey-reoviruses> DOI: 10.1637 /10779-012314-Reg.1.

MOREIRA, G. N., REZENDE, C. S. M., CARVALHO, R. N. MESQUITA, S. Q. P. DE OLIVEIRA, A. N., ARRUDA, M. L. T. Ocorrência de Salmonella sp. em carcaças de frangos abatidos e comercializados em municípios do estado de Goiás. Revista Instituto Adolfo Lutz. São Paulo - SP, v. 67, n. 2, p. 126-130, 2008. Disponível em< http://revistas.bvs-vet.org.br/rialutz/article/view/7174>

MOREIRA, M. D.; SUEHARA, R.; BORGES, F. A.; MOREIRA, P. F. S. D. Principais causas de condenação de frangos em abatedouro de aves e coelhos no Triângulo Mineiro. Revista Higiene Alimentar. Mirandópolis - SP, v. 23, n. 170, p. 110-114, mar-abr. 2009. Disponível em < http://pesquisa.bvs.br/brasil/resource/pt/lil-558021>.

NÄÄS, I. A., PAZ, I. C. L. A., BARACHO, M. S., DE MENEZES, A. G., DE LIMA, L. A. O.; BUENO, L. G. F., NETO, M. M., CARVALHO, V. C., I. C. L. ALMEIDA, DE SOUZA, A. L. Medida de deficiência locomotora em frango de corte. Science Agricola. Piracicaba - SP, v.67, n.2, p.129-135, mar./apr. 2010. Disponível em < 
http://www.scielo.br/scielo.php?script=sci_arttext\&pid=S0103-90162010000200001 > DOI: 10.1590/S0103-90162010000200001.

OECD and FAO (2015), OECD-FAO Agricultural Outlook 2015, OECD Publishing, Paris. Disponível em <http://dx.doi.org/10.1787/agr_outlook-2015-en e também no site: http://www.fao.org/3/a-i4738e.pdf>. Acesso em: 19 abr. 2016.

OH, J. Y. , KANG , M. S. , AN , B. K., SONG, E. A. , KWON, J. K. KWON, K. Occurrence of purulent arthritis broilers vertically infected with Salmonella enterica serovar Enteritidis in Korea. Poultry Science. Oxford, v. 89, p. 2116-2122, 2010. Disponível em < https://www.ncbi.nlm.nih.gov/pubmed/20852102>. DOI: 10.3382/os.2010-00918.

OliVeIRA, A. A., ANDRADE, M. A., ARMENDARIS, P. M., BUENO, P. H. S. Principais causas de condenação ao abate de aves em matadouros frigoríficos registrados no serviço brasileiro de inspeção federal entre 2006 e 2011. Ciência Animal Brasileira, Goiânia - GO, v.17, n.1, p. $79-89$ jan./mar. 2016. Disponível em < http://www.scielo.br/pdf/cab/v17n1/1809-6891-cab-17-01-0079.pdf>. DOI: 10.159010 89-6891v17i123020.

RASHEED, B. Y. Isolation and identification of bacteria causing arthritis in chickens. Iraqi Journal of Veterinary Sciences. Mosul Iraq, v. 25, n. 2, p 93- 95, 2011. Disponível em < http://vetmedmosul.org/ijvs/media/11-2-10e.pdf>.

RECK, C., MENIN, A., PILATI, C., MILETTI, L.C., Características clínicas e anatomohistopatológicas da infecção experimental mista por Orthoreovirus aviário e Mycoplasma synoviae em frangos de corte. Pesquisa Veterinária Brasileira, Seropédica-RJ, v. 32, n. 8, p. 687-691, 2012. Disponível em < http://www.scielo.br/scielo.php?script=sci_arttext\&pid=S0100-736X2012000800001> DOI: 10.1590/S0100-736X2012000800001.

REVOLLEDO, L.; FERREIRA, A. J. P. Patologia aviária. Barueri - SP: Manole, 2009. 510p.

RODRIGUES, D. P., THEOPHILO, G. N. D., REIS, E. M. F., LÁZARO, N. S. Doenças de transmissão alimentar: aspectos clínicos, coleta e transporte de material. Instituto Osvaldo Cruz - FIOCRUZ, 2008, 90p.

SILVA, I.J.O., VIEIRA, F.M.C. Ambiência animal e as perdas produtivas no manejo pré abate: o caso da avicultura de corte brasileira. Archivos de zootecnia. Córdoba, v. 59, p. 113-131, 2010. Disponível em < http://www.scielo.br/scielo.php?script=sci_ nlinks\&ref=000122\&pid $=S 1415-4366201400040001400019 \&$ lng $=e m>$.

TAVARES, L. P. RIBEIRO, K. C. S. Desenvolvimento da avicultura de corte brasileira e perspectivas frente à influenza aviária. Organizações Rurais \& Agroindustriais, Lavras - MG, v. 9, n. 1, p. 79-88, 2007.

VASCONCELOS, S. B.S.; BOTTINO, J. A.; GUERRA, J. L.; JEREZ, J.A. Lesões articulares em frangos de corte (Gallus gallus) na infecção experimental pelo 
reovírus aviário. Brazilian Journal of Veterinary Research and Animal Science. São Paulo - SP, v.38, n.2, p.80-83, 2001. 